\title{
An 'alternative' in Germany
}

\section{Frelburg, Germany}

A new $\$ 69$ million cancer research centre now being built in Freiburg could help bring clinical cancer research in Germany out of its current doldrums. The Tumour Biology Centre, which is expected to open its doors in early 1993, is the first largescale attempt in Germany to wed clinical cancer medicine with basic science - an approach that has gained wide favour in the United States and Britain and that has been urged by German research organizations for years, but to limited effect.

Despite its promise, however, there are serious doubts about whether the centre can succeed in its current form. It owes its existence to a promise by its director to study 'alternative' cancer treatments, and German researchers not affiliated with the centre question how easily it can attract serious scientists if this promise is kept.

The founding director, Gerhard Nagel, a respected oncologist who gave up a chair at the University of Göttingen to start the centre, raised funds from a variety of sources including three pharmaceutical companies and a bank.

But the contribution that has caused the most comment among other researchers is the DM25 million from the Land of Baden-Württemberg, which has also agreed to provide DM2 million a year for operating costs. Nagel specifically promised politicians from BadenWürttemberg that the centre would look into unconventional treatments - a promise he intends to keep. "We will take alternative medicine seriously and put it to the test," he says.

But it will be a tricky task for Nagel to keep his promise without alienating mainstream researchers. "If [Nagel] starts to test herbs and juices on people [to the exclusion of real science], he will lose his reputation overnight," says Sabine von Kleist, director of the institute for immune biology at the University of Freiburg. Von Kleist's view has been echoed by cancer researchers across Germany.

Nagel has assured colleagues that he will use only scientific methods in studying both conventional and unorthodox treatments. "We will not touch treatments that cannot be tested scientifically," he asserts.

More than just the future of the centre depends on how well Nagel is able to balance the conflicting demands placed on him. If it succeeds, the new centre which will focus on tumours of endocrine origin and will include both a 200-bed clinic and a research branch concentrating on clinical pharmacology - offers a way to cast off the institutional shackles that have prevented Germany from doing more cutting-edge research in clinical medicine.

University politics has traditionally been the biggest hurdle to achieving better clinical research in German hospitals. Because of the way clinical research is organized at universities, physicians are usually overwhelmed with responsibilities for teaching and patient care which leave them little time to do research.

Furthermore, clinic directors are entitled to share in the clinic's profits from private patients, so they have little incentive to reinvest those profits in research.

The Nagel centre manages to overcome both these disadvantages. Staff members at the Freiburg centre will not have teaching responsibilities (although they may teach if they choose), and the profits from the clinic will all be put back into the research effort, Nagel says.

Nagel's centre is also innovative in its financing scheme, which brings in outside investors. He has offered his three pharmaceutical backers - Asta Pharma of Frankfurt, Schering of Berlin and CibaGeigy of Basle - first right of refusal on any new compounds to emerge from the centre. Although this funding mechanism has existed for years in the United States,

\section{Barking up the right tree}

THIS photo does not depict the work of giant squirrels, but rather the damage caused by a band of Oregon poachers harvesting bark from Pacific yew trees Taxus brevifolia. The bark contains the drug taxol,

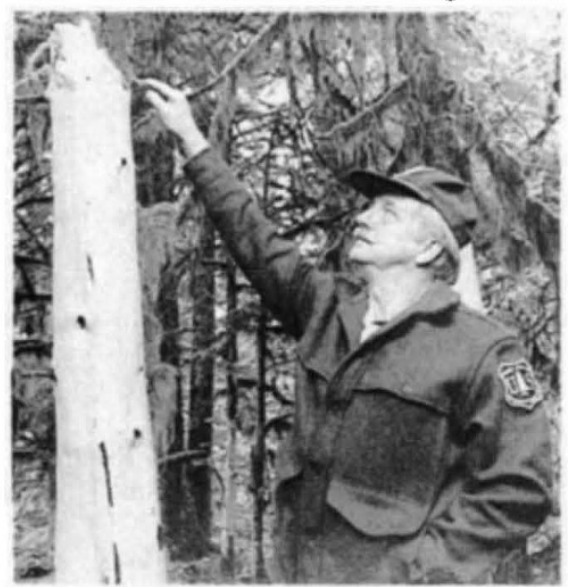
which is showing great promise in clinical trials as an anti-cancer agent, creating a burgeoning demand for the bark.

The US Forest Service, which oversees the national forests in the northwestern United States where many of the yew trees are found, is offering a $\$ 10,000$ reward for information that helps to catch the poachers. The service signed an agreement last month with the drug company Bristol-Myers Squibb to it is unheard of in Germany, where state-owned university hospitals are not allowed to make such arrangements.

A further source of financing may turn out to be the producers of the so-called 'alternative' cancer treatments, which range from extracts of mistletoe and extracts from the thymus glands of animals to 'fresh-cell therapies' which involve the injection of sheep cells into the body. The field of 'alternative medicine' in general, which includes homoeopathy and herbal medicine, commands a huge market in Germany, where almost every pharmacy also dispenses homoeopathic remedies. If Nagel manages to stay on the good side of the producers of alternative treatments, they may provide a rich untapped market for the financing of further clinical trials.

In the end, the future of the centre will depend on the quality of the scientific staff it can attract, and that in turn will depend very much on Nagel, a respected but rather mercurial character of whom other researchers tend to be wary, if not downright suspicious. Privately, they say they wonder if picking a path for the new clinic that avoids the many pitfalls may be too much for even him.

Steven Dickman supply yew bark for taxol extraction, and spokesman Jim Sanders says all harvesting must be coordinated through the new agreement. Bark poaching has so far been a small problem - with the number of trees attacked only in the hundreds - but the Forest Service wants to ensure that it does not get out of hand.

Over the coming year, the National Cancer Institute hopes to treat 12,000 cancer patients with taxol, either as part of the continuing clinical trials or for 'compassionate release' of the drug to severely ill patients, says Jason Fisherman from the institute's Investigational Drug Branch. This will require up to 40,000 trees, from the approximately 23 million in the states of Washington and Oregon.

Eventually, taxol may be produced without the need to sacrifice yew trees. Saul Schepartz, from the cancer institute's Developmental Therapeutics Programme, expects taxol extraction from yew needles to become significant within three years. And if experimental cellculture techniques can be developed on a commercial scale, the demand for the bark may be over in five years.

Taxol fights tumours by inhibiting the formation of normal mitotic spindles, thus reducing cell proliferation.
P.A. 